\title{
HACIA UNA ECOLOGÍA POLÍTICA DE LA BICICLETA
}

\author{
Santiago GOROSTIZA \\ Universidade de Coimbra (Portugal) \\ sgorostiza@gmail.com
}

\section{TOWARDS A POLITICAL ECOLOGY THE BICYCLE}

Reseña del libro de James Longhurst, Bike Battles: A History of Sharing the American Road. 2015, Washington University Press.

Hacia el final de Bike Battles, James Longhurst confiesa haber engañado al lector con el título. No hay en marcha, desde su punto de vista, una guerra entre los usuarios de la calle, ni verdaderas batallas que combatir. El uso de esta palabra es una licencia dramática para expresar, en toda su amplitud, la idea de una continua negociación política por las calles, por el espacio público. No hay duda que Bike Battles es un título mucho más atractivo de lo que hubiera sido "Una selección de debates sobre política ciclista", pero a esas alturas del excelente libro de Longhurst la cuestión es ya irrelevante. En las seis historias presentadas por el autor -desde la lucha por el uso de las calles a finales del siglo XIX hasta el boom ciclista de la década de 1970 - queda patente la crudeza y violencia con la que estas "negociaciones políticas" se pueden reflejar en la documentación de archivo, la prensa impresa y el mismo espacio urbano. La licencia, por lo tanto, resulta perfectamente apropiada.

Hay, sin embargo, un segundo engaño, más flagrante si cabe, que incumbe a la otra palabra que completa el título: las propias bicicletas. Y es que como el autor reconocía en una reciente entrevista, fue cuando estaba leyendo sobre las discusiones en relación a los impuestos a la circulación ciclista durante la década de 1890, la distribución de los recursos recaudados y el bien común cuando Longhurst empezó a razonar que la cuestión central no era para nada la bicicleta ${ }^{1}$. El tema fundamental eran las calles, las carreteras, entendidas como un recurso común del que todos los usuarios pueden obtener provecho. ¿Cómo había cambiado la regulación en el acceso a este recurso a lo largo del tiempo? Bike Battles, como anuncia fielmente -esta vez sí- el subtítulo del libro, traza la trayectoria del uso de este recurso, la calle, y el modo en cómo sus usuarios lo han compartido en Estados Unidos desde 1870. Con gran atención, por supuesto, al papel de la bicicleta. En otros términos, Bike Battles narra la irrupción, expulsión y lenta reintroducción de los ciclistas a las calles estadounidenses mediante seis episodios históricos.

Esta es posiblemente la gran aportación del trabajo de Longhurst: la aplicación de las ideas de Elinor Ostrom sobre los bienes comunes a la historia de la bicicleta, o mejor di-

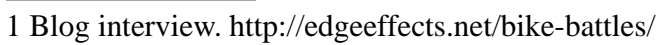


cho, a las propias calles -y el espacio ocupado por los ciclistas en ellas. El término roads, dicho sea de paso, transmite en inglés el significado de "calles" así como el de "carreteras". Longhurst estima que si bien los debates sobre el uso de las calles recuerdan a la famosa "tragedia de los comunes" de Garrett Hardin -donde el acceso indiscriminado a un recurso abierto termina por destruirlo de forma no intencionada- la investigación sobre los comunes ha caminado mucho desde que dicho autor publicó su trabajo en 1968. Es aquí donde hace valer el trabajo de Ostrom (1990) y otros investigadores como Derek Wall (2014) para mostrar como antropólogos y economistas, entre otros, han estudiado los sistemas de regulación, acceso y gestión de los recursos comunes creados por distintas sociedades humanas desde hace miles de años. Para Longhurst, entender las calles como un recurso compartido y no simplemente como el escenario de una batalla puede ayudar a entender los conflictos sobre su uso, y también a concebir mejor la planificación urbana del futuro. Concebir las calles como un bien común permite alejarse de las acusaciones entre conductores y ciclistas para adoptar una perspectiva más amplia.

No es Bike Battles un libro denso, plagado de disquisiciones teóricas. En la introducción, Longhurst expone su argumento de forma clara y concisa, y a continuación se lanza a analizar distintos episodios de la historia de las calles con una prosa ágil, manteniendo la conexión con su tesis general, y retomando la idea en las conclusiones. El autor -profesor en la universidad de Wisconsin-La Crosse (Estados Unidos), historiador de las políticas ambientales urbanas, ciclista y activista- transmite un espíritu eminentemente práctico, que entiende que el peligro al que están sometidos los ciclistas en las calles de hoy es el resultado de unas determinadas decisiones tomadas en el pasado. Entender esas decisiones, razona, puede ayudarnos a comprender los dilemas actuales en toda su complejidad y, tal vez, a tomar mejores decisiones en el futuro (p. IX). Para Longhurst, pensar la bicicleta desde la historia ambiental implica considerarla como parte de un sistema de transporte que depende de la sociedad, la cultura, la política, la geografía, los recursos naturales, la tecnología y la ley (p. 4). A lo largo del libro, el autor adopta la perspectiva del antropólogo Luis A. Vivanco, que considera las bicicletas son "objetos heterogéneos, multidimensionales y contextuales, insertados en unas determinadas condiciones tecnológicas, relaciones sociales, significados culturales y dinámicas político-económicas" (Vivanco, 2013: xx-xxi, 25-26, citado en Longhurst, 2015:185).

Bike Battles se divide en seis episodios narrados en orden cronológico. A lo largo del primer capítulo se explica la batalla legal llevada a cabo por las organizaciones ciclistas para obtener el estatus legal de vehículo para las bicicletas, y compartir así derechos y responsabilidades con el resto de usuarios de las calles. Esto propiciaría luego que los automóviles obtuvieran sin dificultades este mismo estatus. El siguiente capítulo, centrado en el cambio de siglo, expone las distintas campañas para recaudar impuestos para la mejora de las carreteras y las propuestas para crear una red de caminos paralelos para bicicletas. $\mathrm{La}$ atención se centra aquí en las divisiones sociales y raciales de los ciclistas, cuyos proyectos de infraestructura propia no llegaron a buen fin. Sí fue exitosa, en cambio, la campaña que unió a distintos usuarios de vehículos para que un sistema de impuestos financiara la mejora y pavimentación de calles y carreteras. La contribución de los ciclistas, en parte por sus divisiones internas y también por su estigma de elitistas, quedó ocultada. En aquellos lugares donde la red paralela se había empezado a desarrollar con sistemas de pago voluntarios, esta terminó siendo absorbida por la mejora de las carreteras.

En el tercer capítulo, Longhurst analiza el impacto que tuvieron los grandes beneficiados por la mejora de las calles y carreteras: los automóviles. Durante el primer tercio del siglo XX, la masiva expansión del uso de los coches en Estados Unidos empezó a monopolizar el recurso común de las calles. El propio estatus de la bicicleta como vehículo empezó a ser discutido, y su derecho a compartir las calles pavimentadas puesto en duda. El espacio urbano se empezó a rehacer, adaptándose al automóvil mediante distintas innovaciones. Se 
elevaron las aceras, se pintaron los carriles en el pavimento (a partir de 1915), y se establecieron señales como el STOP o los semáforos, destinadas a asegurar que los coches se detuvieran completamente en los cruces. El hecho de aparcar en la calle-dejar el vehículo ocupando una parte muy relevante de una vía pública, compartida con otros usuarios, algo inverosímil años atrás- se convirtió en algo común. Todos estos cambios moldearían la experiencia de los ciclistas durante décadas por venir, y los apartaron, en el mejor de los casos, del centro de la calle a su lado derecho. Pero en primera instancia, los más directamente afectados fueron los peatones, que fueron literalmente expulsados a las aceras y sujetos a multas en caso de cruzar por espacios no designados para ello.

La Segunda Guerra Mundial mostraría las alternativas de forma efímera. Longhurst aborda este periodo en el cuarto capítulo del libro, uno de los más interesantes. Con la finalidad de ahorrar materiales y combustibles, el gobierno estadounidense promovió el uso de la bicicleta y realizó detallados estudios sobre la eficiencia energética de distintos sistemas de transporte, comparando la bicicleta con el coche con resultados muy positivos para la primera. Aunque se mantuvo la libertad de usar el transporte que se prefiriera, el racionamiento de combustible y la propaganda en favor de la bicicleta contribuyeron a un significativo aumento en su uso. Como los Victory Gardens o el fomento del reciclaje, la Victory Bike se convirtió en un símbolo de la unidad en tiempos de guerra. Sin embargo, como señala acertadamente Longhurst, pedalear no era patriótico en sí mismo: lo era en tanto que suponía renunciar al transporte en automóvil. Por ello, esta efímera experiencia pudo contribuir a que las bicicletas adquirieran a posteriori una imagen vinculada al racionamiento y los sacrificios del periodo bélico. El final de la guerra reforzaría los procesos iniciados antes de la misma.

En el quinto capítulo ("El síndrome de los años 50”), Longhurst narra la marginación de la bicicleta en un contexto de energía barata y construcción a gran escala de carreteras y suburbios residenciales. En el caso de las autopistas interestatales, la bicicleta quedó absolutamente excluida, con lo cual ciertos usuarios motorizados obtuvieron acceso exclusivo a un recurso común financiado por el conjunto de los ciudadanos. En paralelo, la bicicleta desapareció de las vidas adultas para convertirse en un juguete, un proceso ya iniciado en la década de 1930, que presentaba a la bicicleta como el paso previo necesario a la adquisición de una motocicleta o automóvil y asimilaba esta substitución a la transición de la infancia a la edad adulta. En este capítulo, el uso de las fuentes documentales es especialmente original. Con la bicicleta más y más ausente en la legislación y la prensa, Longhurst acude a las revistas infantiles, las series televisivas y los documentales educativos estadounidenses.

El sexto capítulo está dedicado al boom ciclista de la década de 1970 y su relación con la primera y segunda crisis del petróleo. Longhurst muestra como después de casi medio siglo de un sistema legal y político de gestión de las calles y carreteras construido alrededor del automóvil, el retorno de la bicicleta no podía ser fácil ni exento de conflicto. Además, el autor juzga que la mayor parte de iniciativas llevadas a cabo fueron parciales, contradictorias y carentes de un liderazgo fuerte, lo que imposibilitó verdaderos cambios.

En síntesis, Bike Battles presenta como durante el siglo XX los conductores de automóviles estadounidenses lograron afianzar su control sobre las calles y carreteras, que hasta entonces habían sido compartidas por una variada cohorte de usuarios. Las continuas disputas sobre el derecho de los ciclistas a usar este recurso son, para Longhurst, "un síntoma de los desafíos que implica la gestión de un recurso que según los principios legales debería ser accesible para todos" (p. 12). El libro es una encantadora historia ambiental de las bicicletas en las calles y carreteras americanas desde 1870, escrito con un estilo fluido, con una sólida investigación archivística, un uso original de las fuentes documentales y una edición generosamente ilustrada. En términos teóricos, tal vez dejará hambrientos a aquellos familiarizados en el estudio de los comunes. Pero deja servida una interpretación basada en la ecología política, con una sólida perspectiva histórica, que atienda a las relaciones de poder 
implicadas en la ocupación de las calles y a los beneficiados y marginados por su regulación. Además, para muchos lectores, no necesariamente interesados en debates académicos, Bike Battles puede aportar una nueva y fresca mirada a las calles y carreteras. Para afrontar los dilemas actuales y los planes futuros, es posible encontrar inspiración en el pasado.

\section{Bibliografía}

OSTROM, Elinor.

1990 Governing the Commons: The Evolution of Institutions for Collective Action. Cambridge: Cambridge University Press.

VIVANCO, Luis A.

2013 Reconsidering the Bicycle: An Anthropological Perspective on a New (Old) Thing. New York: Routledge.

WALL, Derek.

2014 The Commons in History: Culture, Conflict and Ecology. Cambridge, MA: Mit Press, 2014. 